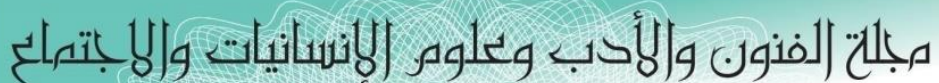

Journal of Arts, Literature, Humanities and Social Sciences

ISSN online: 2414 - 3383

ISSN print: 2616 - 3810

أيلول -سبتمبر 2019

العدد (42)

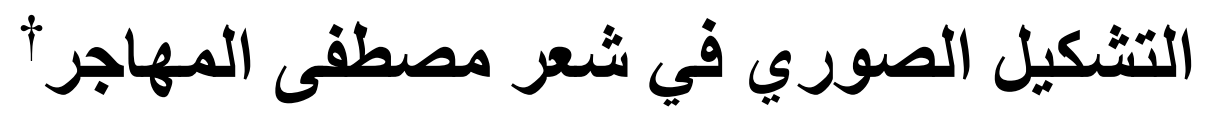

$$
\begin{aligned}
& \text { أ.د. كريم مهدي المسعودي } \\
& \text { جامعة القادسية ـ كلية الآداب }
\end{aligned}
$$

\author{
مريم جبار تومان \\ جامعة القادسية _ كلية التربية \\ mariam.jabar.94@gmail.com:الإيميل
}

\title{
Formation in the Poetry of Mustafa Al-Muhajir
}

\begin{abstract}
This study is concerned with the study of morphology in the poetry of Mustafa AlMuhajir, the Iraqi poet who fled his homeland because of the oppression of power. This composition dominates some of the poems of the Muhajir. He establishes bases that can be monitored and described through the process of objective and artistic analysis through imagination and passion. Because they are considered an important tributary of the tributaries of creativity that counts for the poet as we saw his hair Full of emotions and sincere emotions that rose in us surprising and we touch the formations of life in his poet.
\end{abstract}

† بحث مستحل من رسالة الماجستير الموسومة : شعر مصطفى المهاجر - الرؤية و التشكيل. 


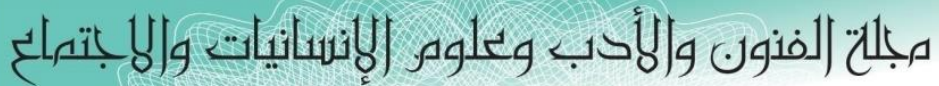

Journal of Arts, Literature, Humanities and Social Sciences

ISSN online: 2414 - 3383

ISSN print: 2616 - 3810

\section{العدد (42) ايلول - سبتمبر 2019}

تُعد - الصورة الثعريةــ من العناصر المهمة و المؤثرة في التشكيل الثعري فهي تعبر عن تجربـة القصد لديـه

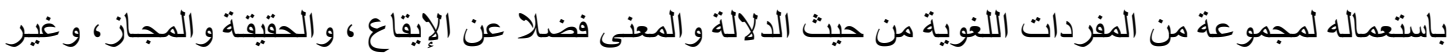

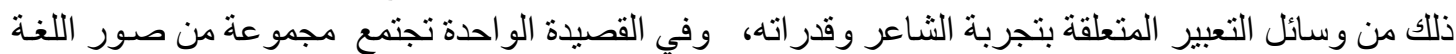

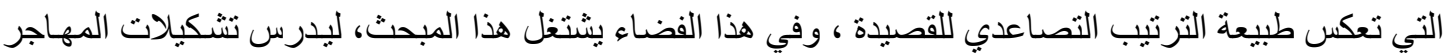

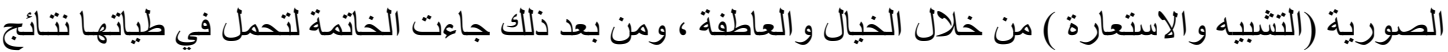

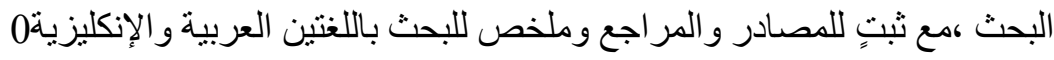

التثكيل الصوري

يعرف كمال ابو ديب بمفهومين للصورة الفنية من حيث التشكيل : الاول قديم يجسد فيه الصور البلاغية من

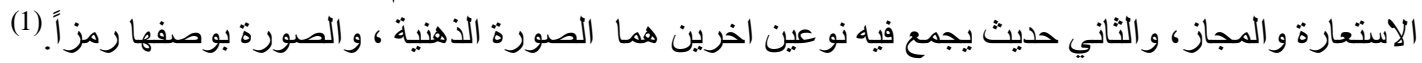
وبهذا يحاول الثـاعر انجاح نصها الثُعري وايصاله إلى المتلقي، ولعل في قول (كولدرج ) ما نرمي إليه في

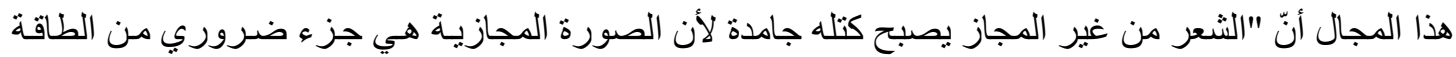

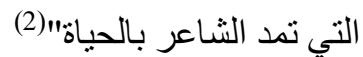

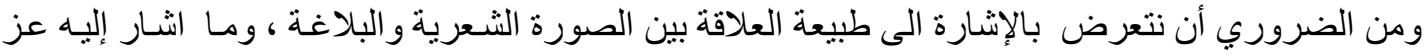

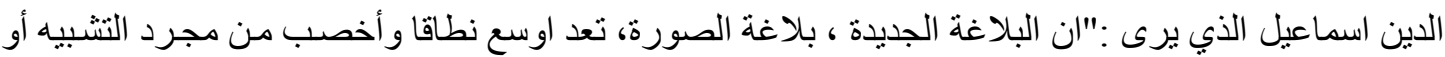

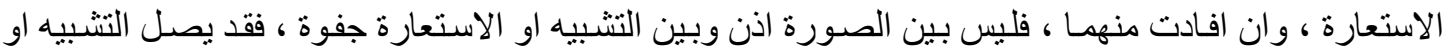
تصل الاستعارة في بعض الاحيان الى درجة الخصب و الامتلاء و العمق الى جانب الاصنالة و الابتداع حيث تمثل

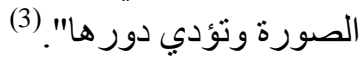

فنحاول أن نرسم صورة موجزة لخيال الثـاعر(المهاجر ) و لا يكون ذللك إلا من خلال القر اءة المعدقة لقصـائده

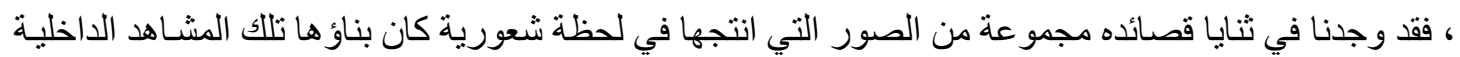
و الخارجية التي أضفت على القصيدة مشاهد متنو عة وصور مختلفة.

وقد تتو عت تعريفات الخيال وتعددت بشكل كبير ، لكنها متقاربة او متشـابهة من حيث المعنى لدى المحدثين

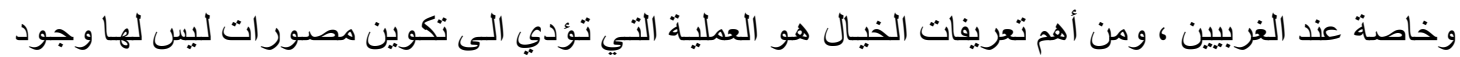

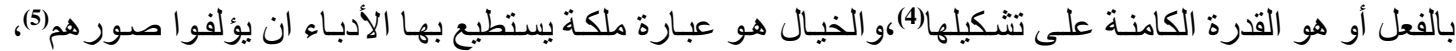

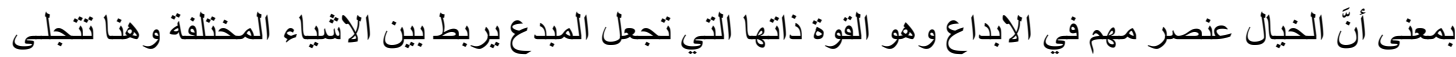

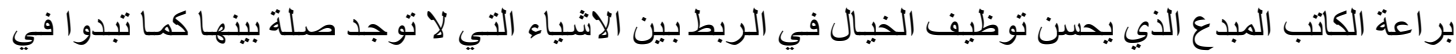

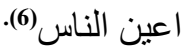

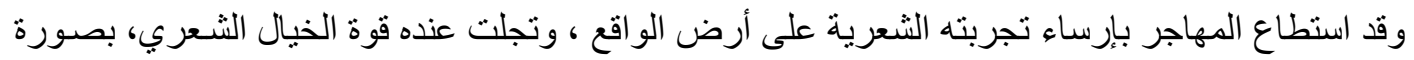

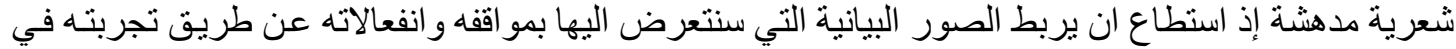
الحياة.

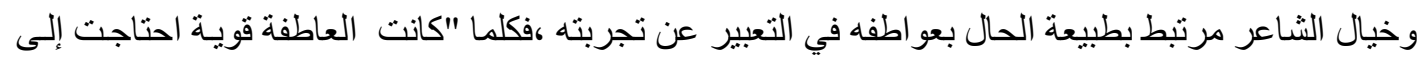
خيال قوي يعين عليها ، وضعف إحداهما يؤثر في ضعف الآخر ،فإذا كانت العو اطف مسرفة مبالغة ذهب الخيال

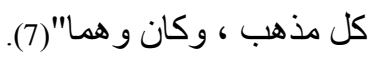




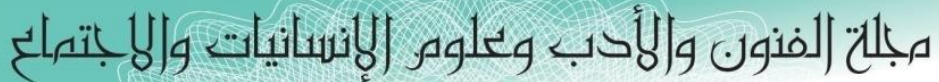

Journal of Arts, Literature, Humanities and Social Sciences

ISSN online: 2414 - 3383

ISSN print: 2616 - 3810

\section{العدد (42) أيلول - سبتمبر 2019}

و العو اطف هي كل انفعالات تثير النفس ، سواء كانت فرحا أم حزنا مثل الرضـا و الحب و الانتقام و الغضب الغناب

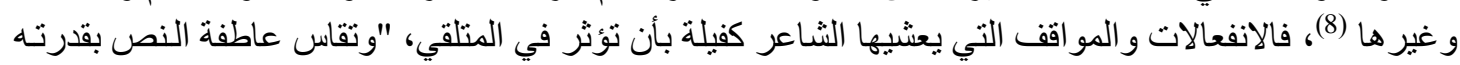

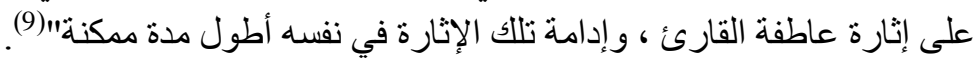

أـ التشبيه

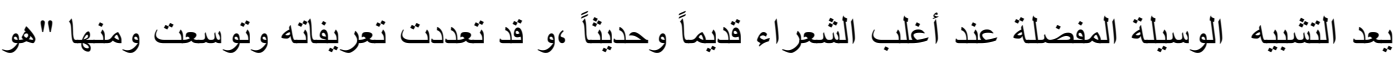

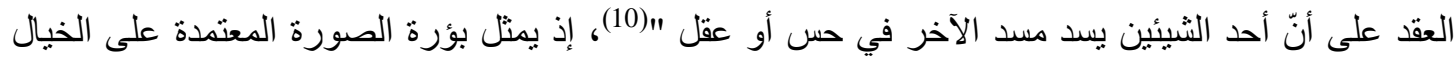

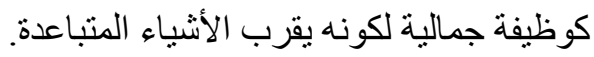

وأول ما يطالعنا من صور التشبيه في قصـائد المهاجر هو اعتمـاد أغلب هذه القصائد على الحواس ، لأنها مادة التصور ، إذ تقرب بين العناصر المتباعدة ولا يحصل ذللك إلا من خلال فكر الثاعر و انفعالاته كما في قوله: وأظل أدور كساقية أو ناعور وأظل أدور كأنغام فرّت من وتر مهجوز وأظل ..أظل

\section{ويغمرني الديجور(11).}

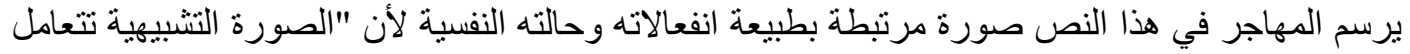
مع الو اقع المحسوس بأبعاده، ومع الجوانب الفكرية ، ومع أعماق الإحساس النفسي الداخلي "(12).

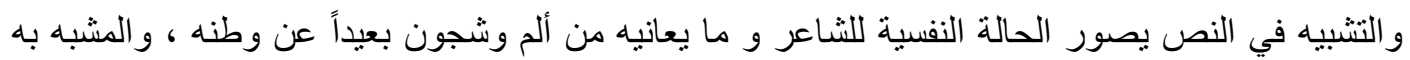

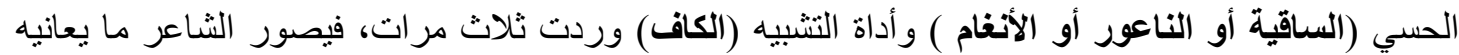

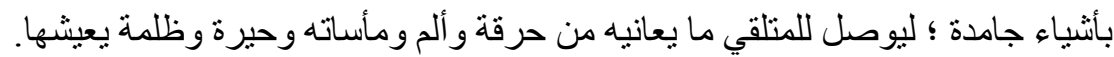
يريد الثّاعر تغييراً على مستوى حياته الذاتية و الاجتماعية ؛لأنه يرى أنَّ لحظات الفرح مسروقة في حياته ، فيثير المتلقي في تعابيره، إذيقول: وها لحظات الفرح الخاطف تذوب سريعاً كنيازك فرّت من مجراتها(13).

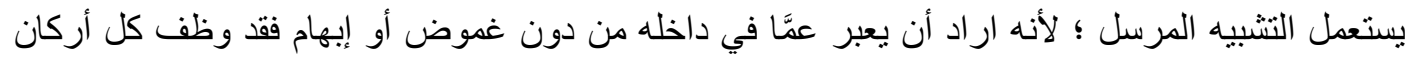

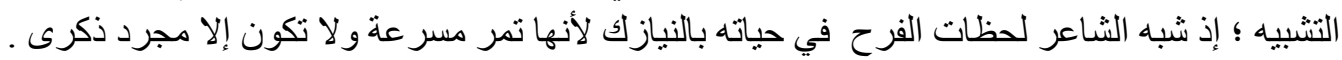

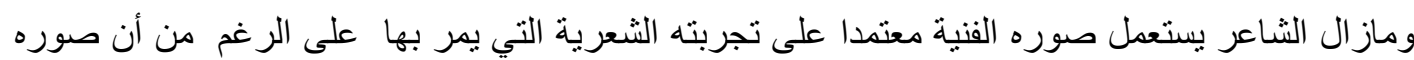

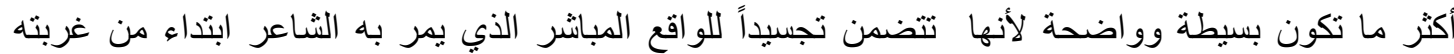

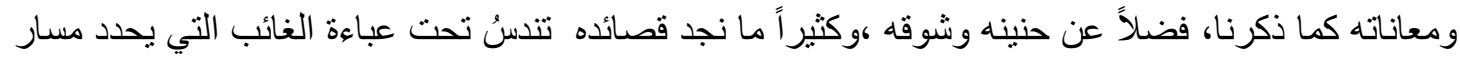




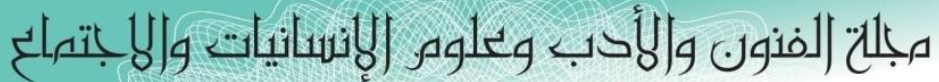

Journal of Arts, Literature, Humanities and Social Sciences

ISSN online: 2414 - 3383

ISSN print: 2616 - 3810

أيلول - سبتمبر 2019

العدد (42)

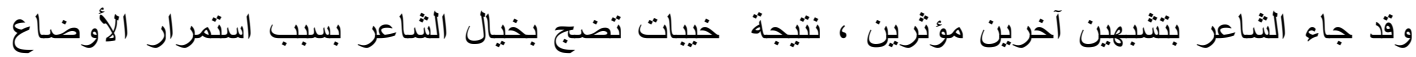

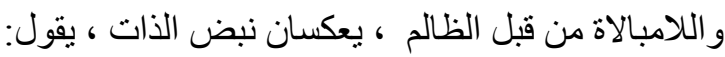

$$
\text { والأمواج ترتجف واب الكثرُ }
$$

إنَّ الأصدقاء و الأحباب و الأصحاب كثيرون ولكن مثل موج البحر غير مستقرين قد تجمعهم الأيام وقد تشتتهم التهر

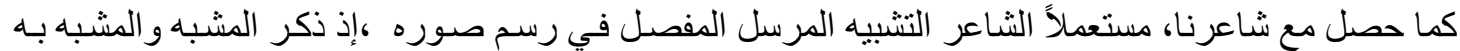
و الأداة ووجه الثبه ترجف، و التشبيه الآخر الصحاب الكثر كالصحر اء الجرداء التي لا مـاء و لا ظل شجر فئه فيها

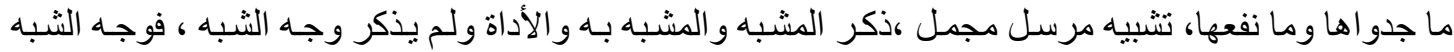

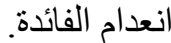

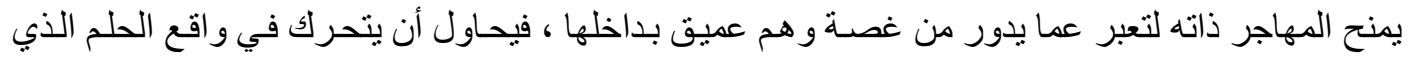
تفرضه إر ادة خارج سلطته وسبيها وجود (الآخر ) المتسلط، فيحاول الثاعر الاندفاع إلى الأمام عن طريق الحلم

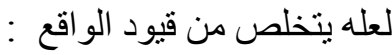

$$
\begin{aligned}
& \text { ما الذي نرجوه .. } \\
& \text { أن يأتي .. } \\
& \text { فياتٔي } \\
& \text { واضحا كالثمس } \\
& \text { أو طيفاً جميلاً } \\
& \text { أو كتهويم شبَّ.؟(15). }
\end{aligned}
$$

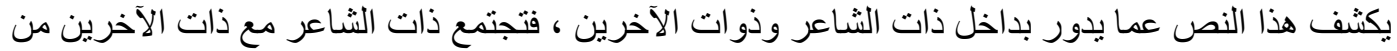

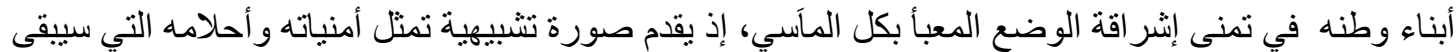

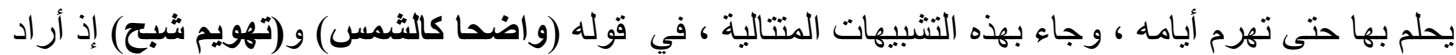

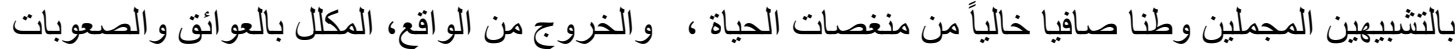
إلى عالم يُشُعره بالسعادة و الأمل، و إن كان عالماً في الأحلام أو يأتيه كالثبح.

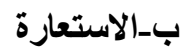

هي "استعمال اللفظ في غير ما وضع له ؛ لعلاقة المشابهة بين المعنى المنقول عنه و المعنى المستعمل فيه ،

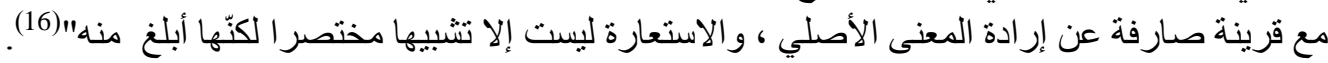


مبلح لفنون والأدب وعلوه الإنسانيات والهبتماك

Journal of Arts, Literature, Humanities and Social Sciences

ISSN online: 2414 - 3383

ISSN print: 2616 - 3810

أيلول - لسبتمبر 2019

العدد (42)

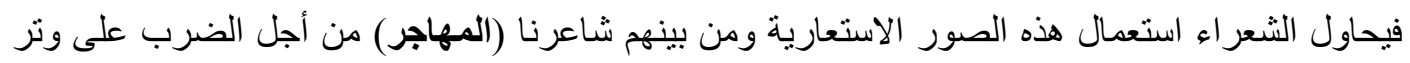

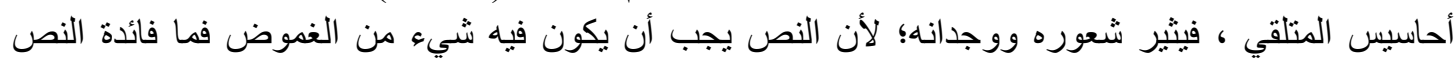

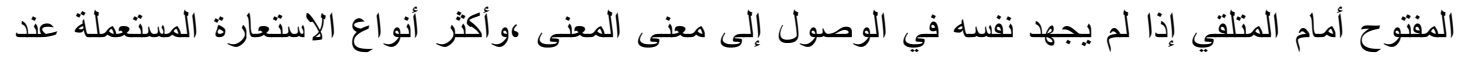

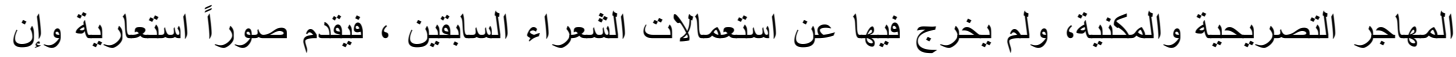

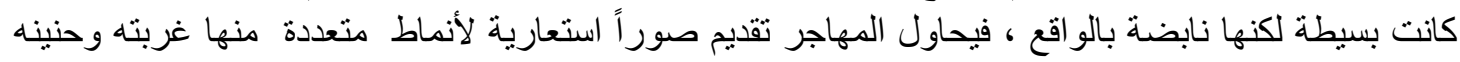

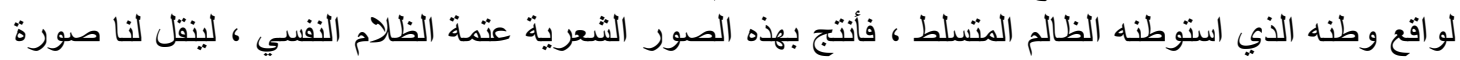
ترسخ حالة العتمة الروحية التي نتجت عن الحكم التسلطي الاستبدادي، إذ يقول:

الريح تبعثر أوراقي

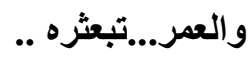

الأيام

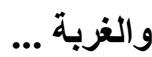

تطوي أحلامي

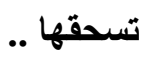

تنفيها ..

هل تبقى في الغربة

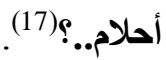

جاء المهاجر بصور نفسية ومعاناة روحية يعيشها، ،مستعملا الاستعارة التصريحية مرة كما في (الريح تبعثر

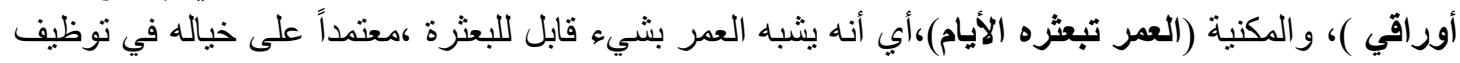

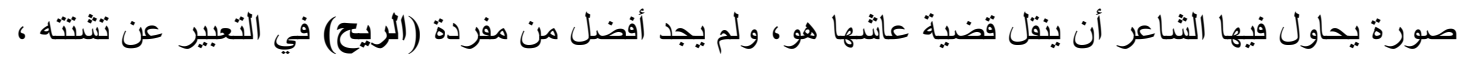

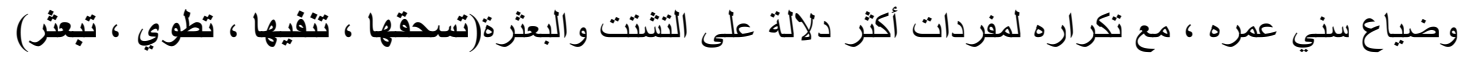
ويستجير باليأس لعدم قدرته على التخلص من هذه الغربة فيتساعل بحسرة وألم (هل تبقى في الغربة أحلام).

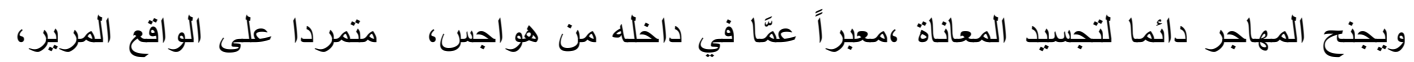

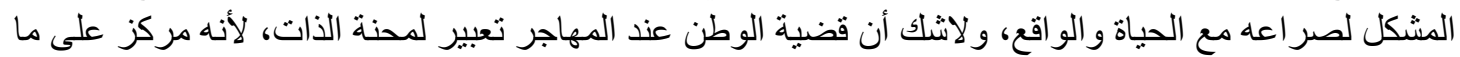

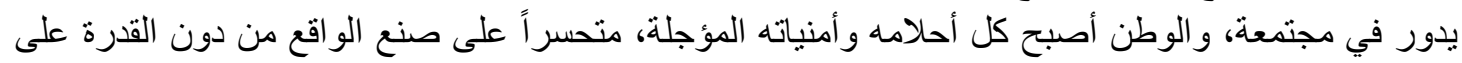

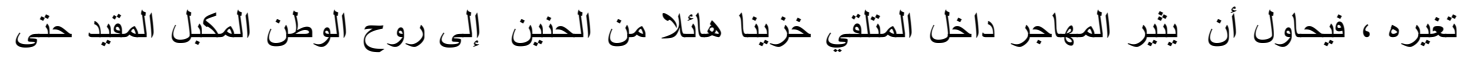

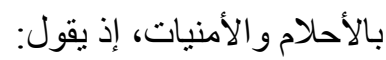

$$
\begin{aligned}
& \text { دعني أقبل } \\
& \text { مسار الدموع } \\
& \text { التي عبرت ذات حزن } \\
& \text { على وجنتيك } \\
& \text { وألقت نغيلات بيتي العتيق }
\end{aligned}
$$




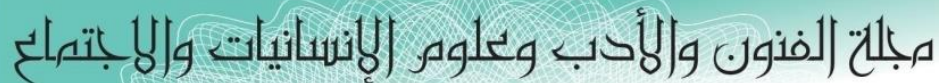
Journal of Arts, Literature, Humanities and Social Sciences

ISSN online: 2414 - 3383

ISSN print: 2616 - 3810

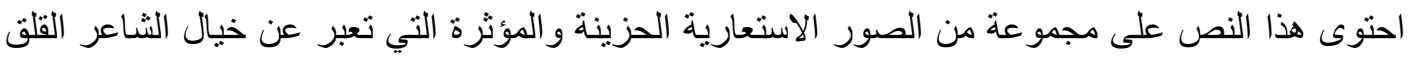

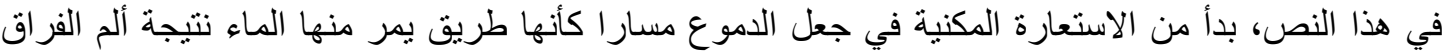

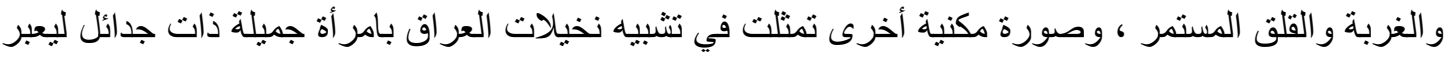

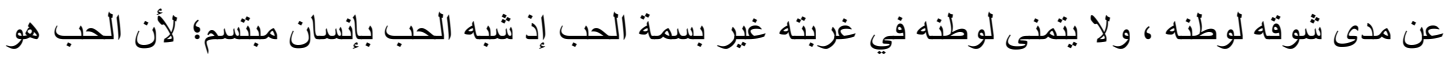

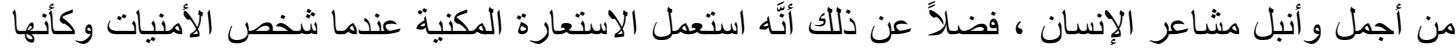

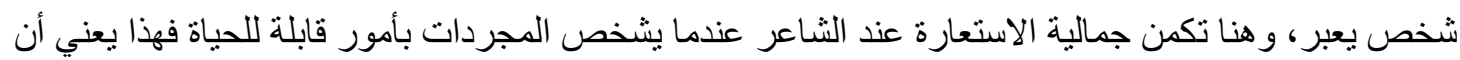
التشخيص يجعل الثيء المجرد كائناً حي يتميز بالحركة ولنئ والحياة(19). يتجه الثشاعر أحيانا لمحاورة الطبيعة ليرسم عليها صور أحز انه و ألمه لعلها تعي مكنوناته النفسية ، مجسداً من

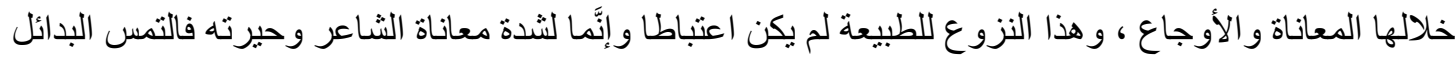
للتعبير عن ألمها، إذ يقول في قصيدة يصف فيها فصل الصيف :

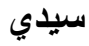
أيها الصيف العراقي

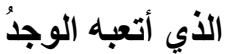
فنام

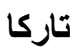
في أفق الأحلام نجمات مواويل وريثات حمام أيها الصيف العراقي الموشى بأطايب الكلام 
مبلح لفنون والأدب وعلوه الإنسانيات والهبتماك

Journal of Arts, Literature, Humanities and Social Sciences

ISSN online: 2414 - 3383

ISSN print: 2616 - 3810

أيلول - لسبتمبر 2019

العدد (42)

خذ لنجماتك

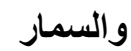

خُذْ لهـا

فيضا من الوجد

وشوقا وهيام (20).

فالثناعر هنا يرسم مشهداً حسياً لمناخ العراق وجمال صيفه، مستعملاً الاستعارة المكنية في النص معتمدا

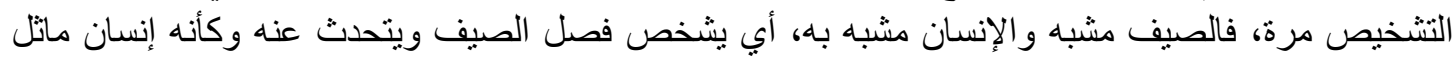

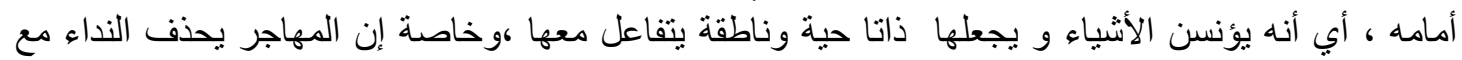

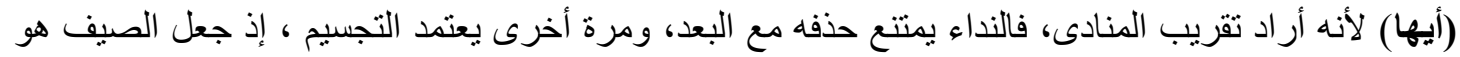

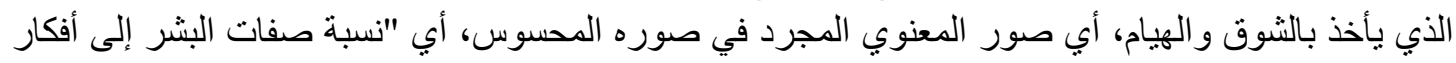
مجردة ، أو أثياء لا تتصف بالحياة "(21).

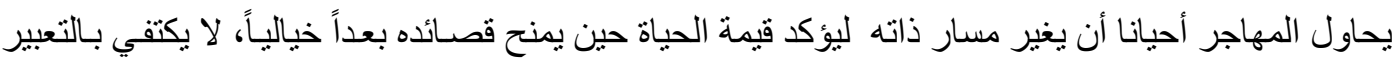

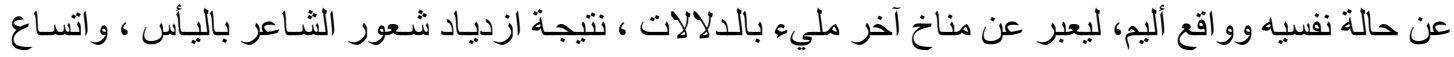
فجوة الهوة بينه وبين الآخر المتسلط ، فاتجه إلى التذكير بصنع الخالق وقدرنه أمام عجز المخلوق و انعدام قدرتها:

نطق الطين بين أصابعها

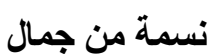

وينطق الموت والصمت

والكلمات الرتيبة

تصبح شعر ا يجلل بالأشعار

شاءت يا الله

أن تصنع الآدميين

وللطين يمنحهم دفأه والجلاز

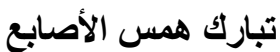

للطين (22).

يعلن الثناعر دهثته من هذا العمل الفني الجميل الذي جسد الحقيقة التي يعلمها الثـاعر وهذا التجسيد نتج من

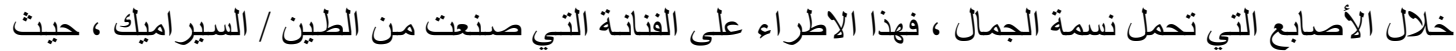

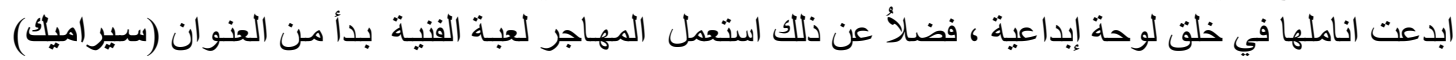

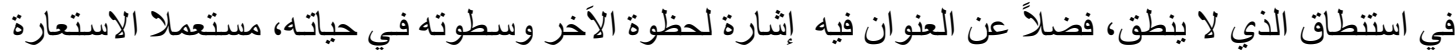

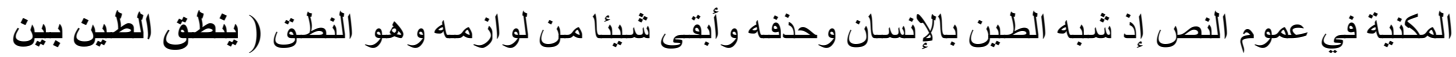




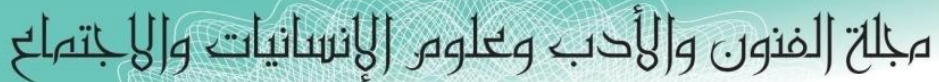
Journal of Arts, Literature, Humanities and Social Sciences

ISSN online: 2414 - 3383

ISSN print: 2616 - 3810

\section{العدد (42) أيلول -سبتمبر 2019}

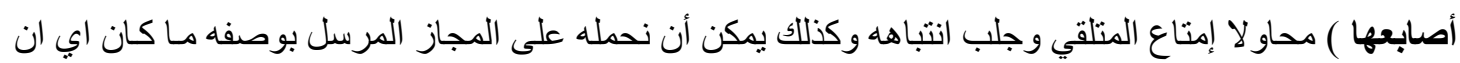

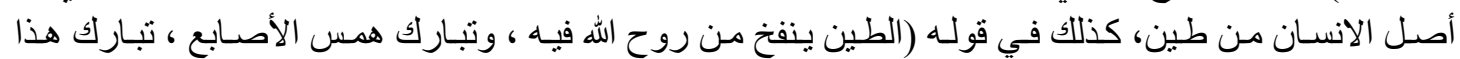

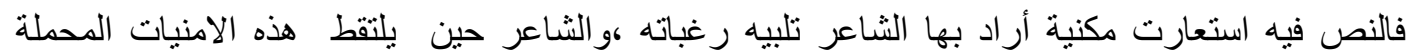

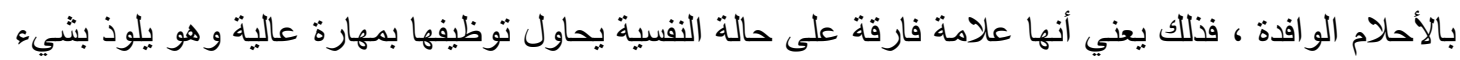

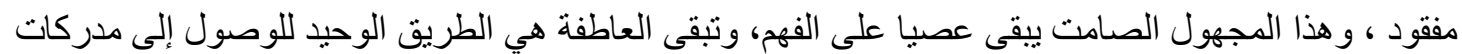
الذات المتثوقة للأخر ، و هذه كلها شحنات دلالية انفعالية ، اسهمت في بناء صور النص بطريقة بديعة وخلّاّةقة

الخاتمة

بعد الفراغ حمده تعالى من دراسة تحليلية أدبية لتنكيل الصورة في شعر المهاجر توصل البحث إلى اهم النتائج:

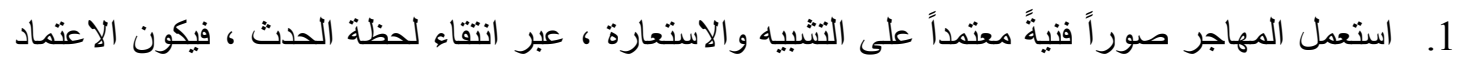

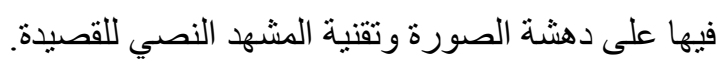
2. صوره أكثر ما تكون بسيطة وواضحة لأنها تتضمن تجسيداً للواقع المباثر الذي يمر به الثناعر ابتداء من

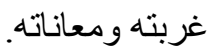
3. جاءت صوره التتكيلية ممزوجة بعو اطفه وانفعالات، لأنها تعبر عن شعور صنادق. 4. صور المهاجر الثعرية أقرب إلى الصورة التقليدية التي وظفها الثعر اءو قبله.

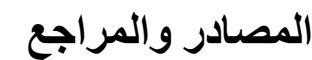

1. الثعر العربي المعاصر قضاياهوظو اهره الفنية والمعنوية ،عز الدين اسماعيل ،دار الفكر العربي ،مصر . 2. 3.

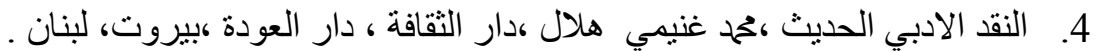

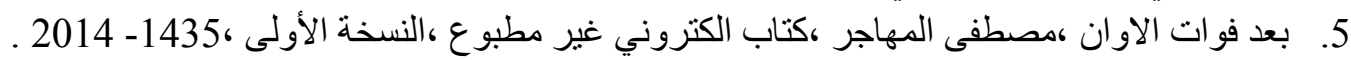
6.

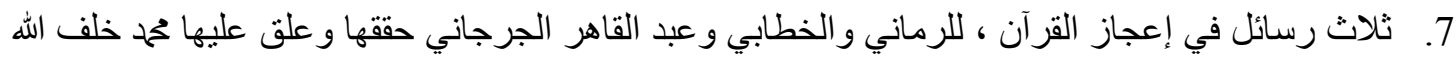

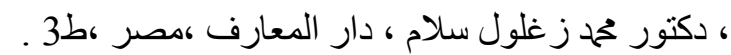

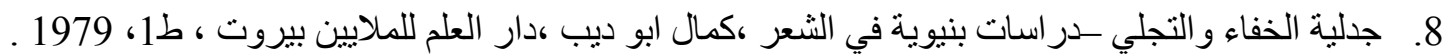

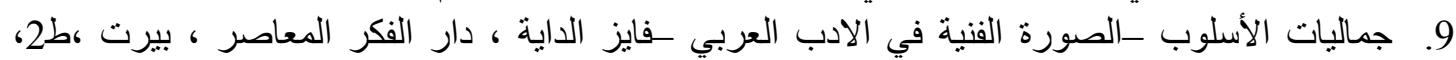
1996

10.جو اهر البلاغة في المعاني والييان والبديع ، السيد أحمد الهاثمي ، دار احياء التراث العربي ، بيروت ،

11. غائب كالوطن ..حاضر كالبكاء ،مصطفى المهاجر ، 1992 . 199

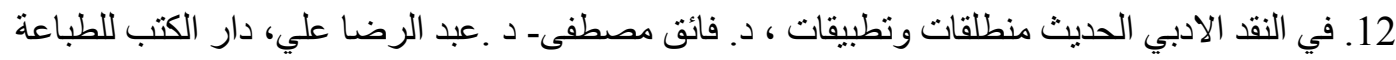

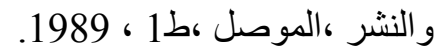
13.في النقد الادبي، د. شوقي ضيف، دار المعارف، القاهرة، ط 9. 


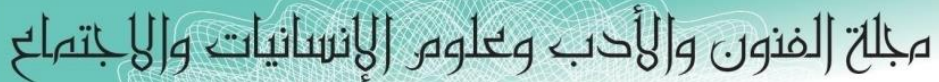

Journal of Arts, Literature, Humanities and Social Sciences

ISSN online: 2414 - 3383

ISSN print: 2616 - 3810

\section{العدد (42) أيلول - سبتمبر 2019}

14. معجم المصطلحات في اللغة والادب ،مجدي وهبة ، كامل المهند ، مكتبة لبنان ، بيروت ،ط8

15. وجع الاسئلة الليلية ،مصطفى المهاجر ،منشورات اتحاد الكتاب العرب، 2000.

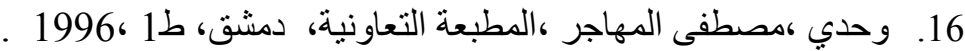

1 2

3

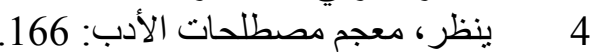

5 5

6

7

8

وتطبيقات : 34.

9

10

11

12 11

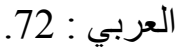

94: 13

14

15

16

17 جواهر البلاغة في المعاني والبيان والبديع :303

303:

18 15: 18

19 19 18

20

215 - 214

22

23 